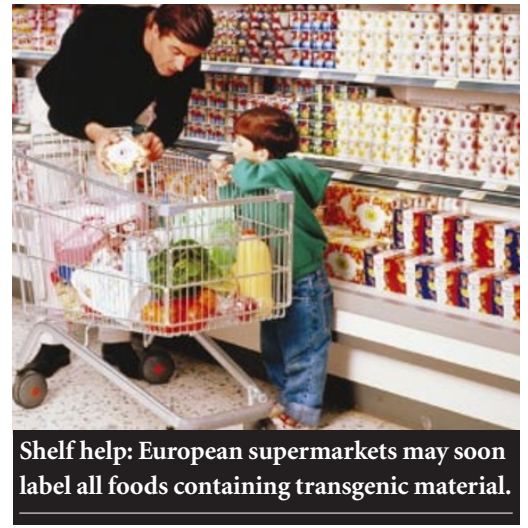

Europe gets tough on labelling genetically modified foodstuffs

\section{Declan Butler, Paris}

Clear labelling of all foods containing material from transgenic organisms may be coming to Europe's supermarkets soon, after the European Parliament backed a proposal to implement it.

The plan, which could be in place within two years, has angered the food industry, which claims that stricter labels would infer a health risk that has not been proved to exist. It could also provoke more trade friction between the European Union and the United States, which strongly opposes such labelling.

On 3 July, the parliament supported a European Commission proposal to increase labelling requirements for foods. It also backed tougher rules than the Commission suggested to test and identify foods and animal feed that have been contaminated with genetically modified material during production or transportation.

The parliament also supported rules that will require manufacturers to trace foods to their place of origin. It narrowly rejected the compulsory labelling of meat, milk and eggs obtained from animals raised on genetically modified feed.

But the parliament voted to cut the threshold above which foods contaminated with transgenic material are classified as genetically modified from $1 \%$ of content to $0.5 \%$. Representatives of the biotechnology industry branded this plan 'unrealistic'.

EuropaBio, an industry group, said in a statement that the parliament's actions would "discriminate against the new technology, reduce consumer choice, disrupt trade with Third World countries, while adding nothing to safety".

But Rachel Sutton of the Consumers' Association in London welcomes the decision. She says that the threshold level for labelling should be continually reduced as testing methods improve.

\title{
Botswana's AIDS laboratory squares up to HIV pandemic
}

\section{Michael Cherry, Gaborone}

With one in three of its adult population infected, Botswana has the highest prevalence of HIV in the world. But in the dusty streets of the capital, Gaborone, there is still hope that the epidemic can be contained.

At the city's Princess Marina Hospital, for example, a dedicated team of 90 scientists and technicians are establishing Africa's largest single laboratory dedicated to AIDS research.

The lab opened its doors at the end of last year, the culmination of a long collaboration between Botswana's government and the Harvard AIDS Institute in the United States.

Most global AIDS research has focused on the HIV-1B virus found in the United States and Europe. So one question being explored by the Botswana lab is whether the HIV-1C virus encountered in Africa has traits that have contributed to its rapid spread through the continent. Researchers in Gaborone now say that more is known about HIV-1C substrains in Botswana than anywhere else.

The laboratory's research has two main objectives: to determine the long-term effects of drug treatment, and to contribute towards the development of an effective vaccine for the virus. The latter aim, in particular, requires the molecular characterization of the strain and a better understanding of the evolutionary development of its 50-plus variants that have been identified in Botswana alone.

To aid the design of a subtype-specific HIV vaccine, cytolytic T-lymphocyte responses and human leukocyte antigen class specificities have been obtained from patients all over the country. Mapping these should provide an indication of the role of genetics in patients' responses to the virus and contribute to vaccine development.

It could also lead to an understanding of whether the pandemic's rapid spread in southern Africa is related to any property of the subtype itself. "It's difficult to tease out the evidence," says Trevor Peter, the lab's manager, "but it appears both to have a higher replicative rate and to be more transmissible,

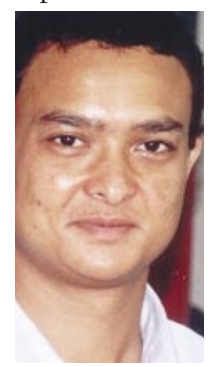

Trevor Peter: on the lookout for evasive evidence. possibly on account of having higher concentrations in body fluids."

Botswana, with a population of only 1.7 million, has no medical school, and most of the lab's senior researchers - including 10 of its 12 clinicians - are foreign. Half of the staff, however, are Botswanan.

Most of the staff are paid on grant money awarded through Harvard,

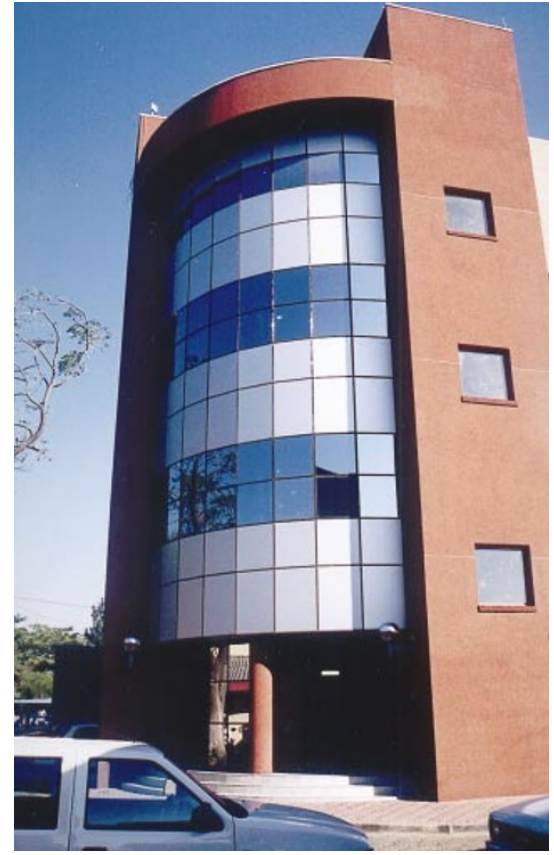

Full house: Gaborone's Princess Marina Hospital is home to a 90-strong team researching AIDS.

and salaries have not hindered recruitment, according to Max Essex, an AIDS researcher at Harvard who was heavily involved in its establishment. The Botswanan government paid about $\$ 3.5$ million to build the laboratory, and charities and drug companies contributed a similar amount to equip it.

Essex says that processing samples locally gives the lab a time advantage over researchers outside Africa, although materials needed to do the work can be slow to arrive.

Hermann Bussmann, who coordinates the lab's research on the impact of anti-retroviral drug treatment of HIV in Botswana, wants to know the extent to which poor adherence to complex anti-retroviral drug regimens will foster resistant strains of the virus. "Resistance will develop," he says, "but hopefully antiretrovirals will buy enough time for a vaccine."

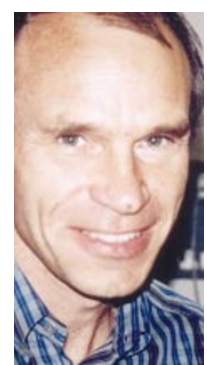

On the front

line: Hermann

Bussmann.
"The partnership between Harvard and the Botswana government is a great model," says Bussmann, who moved to the lab from Germany and is pleased to be "fighting the pandemic in the region where it is most needed". He firmly believes that the fight can be won. "Things may go slowly in Botswana, but at least they go forwards," he says. 